\title{
Parachute Technique for Partial Penectomy
}

\author{
Fernando Korkes, Oseas C. Neves-Neto, Marcelo L. Wroclawski, Marcos Tobias-Machado, \\ Antonio C. L. Pompeo, Eric R. Wroclawski
}

Division of Urology, ABC Medical School, Sao Paulo, SP, Brazil

\begin{abstract}
Purpose: Penile carcinoma is a rare but mutilating malignancy. In this context, partial penectomy is the most commonly applied approach for best oncological results. We herein propose a simple modification of the classic technique of partial penectomy, for better cosmetic and functional results.

Technique: If partial penectomy is indicated, the present technique can bring additional benefits. Different from classical technique, the urethra is spatulated only ventrally. An inverted "V" skin flap with $0.5 \mathrm{~cm}$ of extension is sectioned ventrally. The suture is performed with vicryl 4-0 in a "parachute" fashion, beginning from the ventral portion of the urethra and the "V" flap, followed by the "V" flap angles and than by the dorsal portion of the penis. After completion of the suture, a Foley catheter and light dressing are placed for 24 hours.

Conclusions: Several complex reconstructive techniques have been previously proposed, but normally require specific surgical abilities, adequate patient selection and staged procedures. We believe that these reconstructive techniques are very useful in some specific subsets of patients. However, the technique herein proposed is a simple alternative that can be applied to all men after a partial penectomy, and takes the same amount of time as that in the classic technique. In conclusion, the "parachute" technique for penile reconstruction after partial amputation not only improves the appearance of the penis, but also maintains an adequate function.
\end{abstract}

Key words: penis; penile cancer; surgery; surgical procedures; reconstructive surgical procedures Int Braz J Urol. 2010; 36: 198-201

\section{INTRODUCTION}

Penile carcinoma is a rare but mutilating malignancy. Tumors are often localized in the penis at the time of diagnosis, and they may be better controlled by surgical excision (1-6). In this context, partial penectomy is the most commonly applied approach for best oncological results $(7,8)$. We herein propose a simple modification of the classic technique of partial penectomy, for better cosmetic and functional results.

\section{SURGICAL TECHNIQUE}

After diagnosis of penile carcinoma confirmed by incision biopsy, patients are elected for surgical treatment. When possible, more conservative procedures such as postectomy or glansectomy are performed. If partial penectomy is indicated, the present technique can bring additional benefits. Our Institutional Review Board approved the present study.

Patients are generally operated in the supine position, under spinal anesthetic block. After proper 
asepsis, a surgical glove or condom secured distally to the proposed line of amputation excludes the lesion. A tourniquet is applied at the base of the penis. The skin is incised circumferentially around the penis, deepening to Buck's fascia. The urethra is isolated from the corpora cavernosa and divided, aiming to obtain at least $1 \mathrm{~cm}$ distal redundancy, but without oncological compromise (at least 1-2 cm margin). Dorsal vein complex is ligated, corpora are divided, and the surgical specimen is sent to the laboratory for frozen-section analysis. Corpora are secured with continuous sutures with vicryl 2-0, opposing the margins of Buck's fascia. Tourniquet is removed and adequate hemostasia is obtained.

Different from classical technique, the urethra is spatulated only ventrally. An inverted "V" skin flap with $0.5 \mathrm{~cm}$ of extension is sectioned ventrally. The suture is performed with vicryl 4-0 in a "parachute" fashion, beginning from the ventral portion of the urethra and the "V" flap, followed by the "V" flap angles and then by the dorsal portion of the penis (Figures 1 and 2). After completion of the suture, a Foley catheter and light dressing are placed for 24 hours.

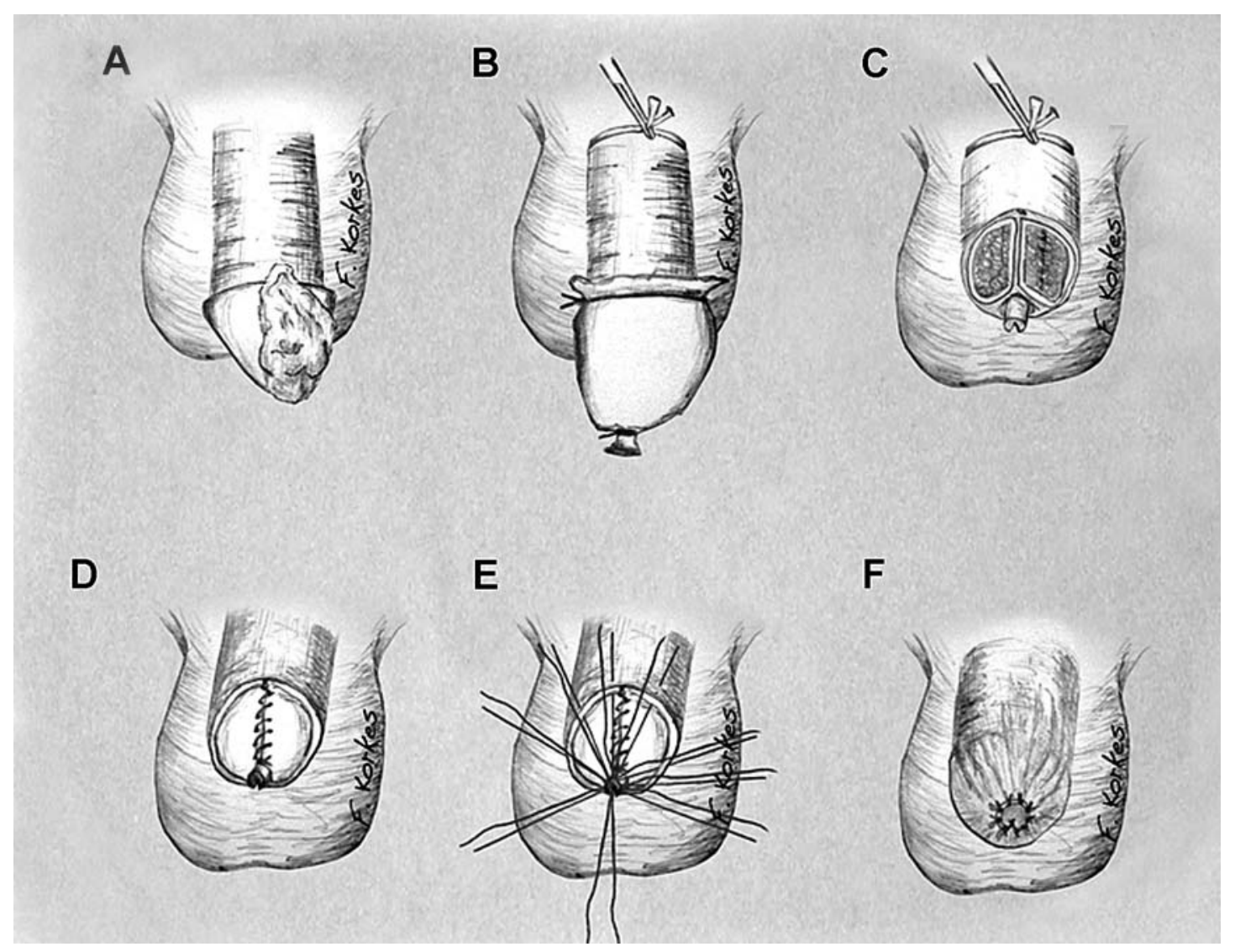

Figure 1 - Schematic drawing of parachute technique for partial penectomy. A) Penile tumor elective for partial penectomy. B) A surgical glove is secured distally to the proposed line of amputation and a tourniquet is applied at the base of the penis. C) Skin is incised circumferentially around the penis, deepening to Buck's fascia, the urethra is isolated from the corpora cavernosa, divided and spatulated only ventrally. D) Corpora cavernosa are closed with continuous sutures with Vicryl 2-0, the tourniquet is removed and adequate hemostasis is obtained. E) Final suture is performed with Vicryl 4.0 in a "parachute" fashion, beginning from the ventral portion of the urethra and the " $V$ " flap, followed by the " $V$ " flap angles and than by the dorsal portion of the penis. F) Final aspect. 


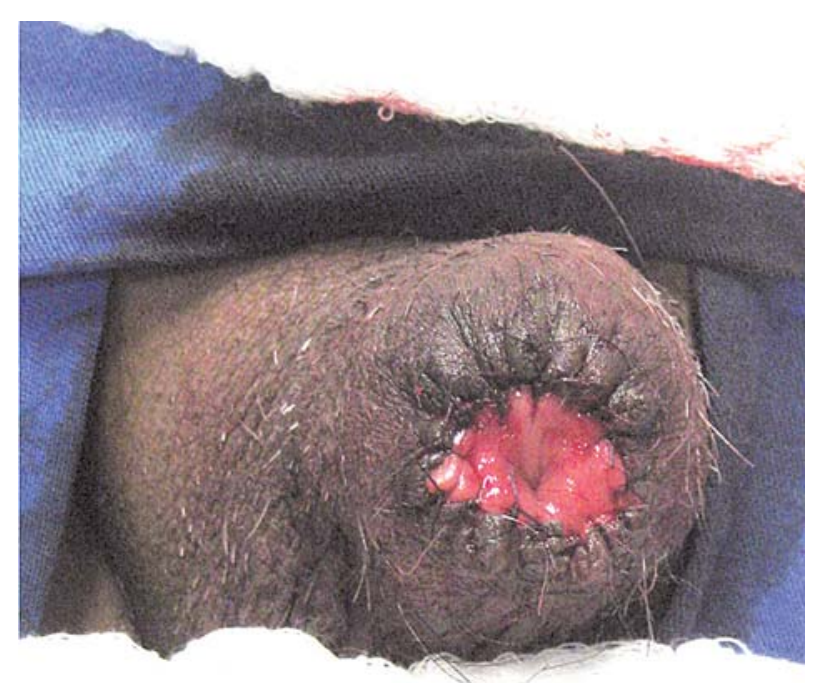

Figure 2 - Final aspect of parachute technique for partial penectomy.

\section{COMMENTS}

After partial penectomy, sexual intercourse and adequate micturition are aims possible to be achieved in most settings. A few authors have evaluated psychological, social and sexual consequences after these procedures (9-11).

The purpose of the present technique is to preserve the morphologic aspect of the penis closer to a normal situation and additionally a permeable meatus. Several complex reconstructive techniques have been previously proposed, but normally require specific surgical abilities, adequate patient selection and staged procedures. We believe that these reconstructive techniques are very useful in some specific subsets of patients. However, the technique herein proposed is a simple alternative that can be applied to all men after a partial penectomy, and takes the same amount of time as the classic technique. We have performed four of such procedures, with good cosmetic aspect after a mean of 8 months of followup. All patients had distal pT2 tumors, two underwent inguinal lymphadenectomy, had positive lymph nodes and died of disease progression after 6 and 15 months; one underwent open inguinal lymphadenectomy without evidence of disease and was lost to follow up after 8 months, and the other underwent laparoscopic inguinal lymphadenectomy also without evidence of disease. No cases of meatal stenosis were observed, and patients were satisfied with the final result, resembling the aspect of a patient with phimosis. Although the present technique has been applied only to a few patients, we are begging a prospective study to evaluate long-term outcomes.

In conclusion, the "parachute" technique for penile reconstruction after partial amputation not only improves the appearance of the penis, but also maintains an adequate function.

\section{CONFLICT OF INTEREST}

None declared.

\section{REFERENCES}

1. Ficarra V, D'Amico A, Cavalleri S, Zanon G, Mofferdin A, Schiavone D, et al.: Surgical treatment of penile carcinoma: our experience from 1976 to 1997. Urol Int. 1999; 62: 234-7.

2. Ornellas AA, Seixas AL, Marota A, Wisnescky A, Campos F, de Moraes JR: Surgical treatment of invasive squamous cell carcinoma of the penis: retrospective analysis of 350 cases. J Urol. 1994; 151: 1244-9.

3. Singh I, Khaitan A: Current trends in the management of carcinoma penis--a review. Int Urol Nephrol. 2003; 35: 215-25.

4. Korkes F, Moniz RR, Castro MG, Guidoni LR, Fernandes RC, Perez MD: Modified inguinal lymphadenectomy for penile carcinoma has no advantages. Journal of Andrological Sciences. 2009; 16: 33-6.

5. Pompeo AC: Extended lymphadenectomy in penile cancer. Can J Urol. 2005; 12 (1 Suppl): 30-6; discussion 97-8.

6. Caso JR, Rodriguez AR, Correa J, Spiess PE: Update in the management of penile cancer. Int Braz J Urol. 2009; 35: 406-15.

7. Kroon BK, Horenblas S, Nieweg OE: Contemporary management of penile squamous cell carcinoma. J Surg Oncol. 2005; 89: 43-50.

8. Tobias-Machado M, Tavares A, Ornellas AA, Molina WR Jr, Juliano RV, Wroclawski ER: Video endoscopic inguinal lymphadenectomy: a new minimally invasive procedure for radical management of inguinal nodes in 
patients with penile squamous cell carcinoma. J Urol. 2007; 177: 953-7; discussion 958.

9. Ficarra V, Mofferdin A, D'Amico A, Zanon G, Schiavone D, Malossini G, Mobilio G: Comparison of the quality of life of patients treated by surgery or radiotherapy in epidermoid cancer of the penis. Prog Urol. 1999; 9: 715-20.

\author{
Correspondence address: \\ Dr. Fernando Korkes \\ Rua Pirapora, 167 \\ São Paulo, SP, 04008-060, Brazil \\ E-mail: fkorkes@terra.com.br
}

\section{EDITORIAL COMMENT}

In this manuscript, the authors describe a novel approach to the surgical management of penile cancer. In this surgical technical report, the cosmetic and functional outcomes of partial penectomy using a ventral spatulation of the urethra and "V" flap technique have been reported. I applaud the authors for their innovative surgical approach, which appears highly reproducible and technically feasible in most cases of penile carcinoma. Although the authors have discussed briefly the four cases in which the "parachute" technique of partial penectomy was utilized, the authors will need to validate their outcomes in a prospective trial in a larger cohort of patients prior to being considered a "superior" surgical approach. Similarly, the authors should obtain an index of erectile function (e.g. IIEF-5) before and following partial penectomy using the standard and "parachute" technique whereby ultimately validating the superior functional outcomes of this reported technique.

Recent advances in the primary management of penile cancer have highlighted that penile preserving approaches can be employed in select patients whereby offering the potential of improved quality of
10. D'Ancona CA, Botega NJ, De Moraes C, Lavoura NS Jr, Santos JK, Rodrigues Netto N Jr: Quality of life after partial penectomy for penile carcinoma. Urology. 1997; 50: 593-6.

11. Hadzi-Djokic J, Dzamic Z, Tulic C, Dragicevic D, Janicic A, Durutovic O: Surgical treatment and quality of life in patients with carcinoma of the penis. Acta Chir Iugosl. 1999; 46 (1 Suppl): 7-10.

Accepted after revision:

October 15, 2009

life and erectile function preservation. Several clinical parameters must be considered when contemplating such penile preserving approaches including the primary tumor stage, grade, location of the penile lesion, and ability to maintain a "functional" penis whereby maintaining the ability to direct a urinary stream and potentially preserve sexual function. As a urologic oncologist, one principle which must never be compromised nevertheless is complete tumor excision with negative surgical margins at the primary tumor site whereby eliminating the nidus for cancer dissemination as well as a potential site of local symptomatic recurrence. As new surgical and technical advances being readily available in our treatment armamentarium, we must ensure that cancer-specific outcomes of these approaches meet the benchmark we have established in the management of this highly aggressive tumor phenotype.

Dr. Philippe E. Spiess Moffitt Cancer Center Tampa, Florida, USA E-mail:Philippe.Spiess@moffitt.org 